\title{
MITIGASI PENCEGAHAN DISORIENTASI SEKSUAL MELALUI PENDIDIKAN KARAKTER BERLANDASKAN NILAI-NILAI KEMUHAMMADIYAHAN PADA GENERASI MILLENIAL
}

\section{MITIGATION OF SEXUAL DISORIENTATION PREVENTION THROUGH CHARACTER EDUCATION BASED ON KEMUHAMMADIYAHAN VALUES IN MILLENIAL GENERATIONS}

\author{
Lilik Kholisotin ${ }^{\text {* }}$ \\ Lailatul Fithriyah \\ Azzakiyah ${ }^{2}$ \\ *IUniversitas Muhammadiyah \\ Palangkaraya, Palangka Raya, \\ Kalimantan Tengah, Indonesia \\ 2IUniversitas Muhammadiyah \\ Palangkaraya, Palangka Raya, \\ Kalimantan Tengah, Indonesia \\ *email: lilikbadir@yahoo.com
}

\begin{abstract}
Abstrak
Penelitian ini bertujuan mencegah LGBT pada generasi millenial melalui pendidikan karakter berlandaskan nilai-nilai Kemuhammadiyahan. Pendekatan penelitian yang digunakan dalam penelitian ini adalah metode pre-eksperimen. Jenis metode eksprimen dalam penelitian ini adalah preeksperimental design dengan menggunakan one group pre-test dan post-test design. Berdasarkan hasil analisis statistik menggunakan paired samples test, diperoleh hasil pretest $\mathbf{5 7 . 4 3}$ dan meningkat pada hasil posttest menjadi I 19.04. Berdasarkan hasil uji paired samples test dapat dikatakan bahwa mitigasi pencegahan disorientasi seksual melalui pendidikan karakter berlandaskan nilai-nilai Kemuhammadiyahan pada generasi millenial efektif mencegah perilaku LGBT.
\end{abstract}

Kata Kunci:

Millenial

Disorientasi Seksual

Karakter

Kemuhammadiyahan

Keywords:

Millennial

Sexual Disorientation

Character

Kemuhammadiyahan

\begin{abstract}
This study aims to prevent LGBT in the millennial generation through character education based on Muhammadiyah values. The research approach used in this research is the preexperimental method. The type of experimental method in this research is pre-experimental design using one group pre-test and post-test design. Based on the results of statistical analysis using paired samples test, the pretest results obtained were 57.43 and increased in the posttest results to 1/9.04. Based on the results of the paired samples test, it can be said that mitigating the prevention of sexual disorientation through character education based on Kemuhammadiyahan values in the millennial generation is effective in preventing LGBT behavior.
\end{abstract}

Accepted

Maret 2021

Published

April 2021

(C) 202 I The Authors. Published by Institute for Research and Community Services Universitas Muhammadiyah Palangkaraya. This is Open Access article under the CC-BY-SA License (http://creativecommons.org/licenses/by-sa/4.0/).

\section{PENDAHULUAN}

Perilaku LGBT sudah ada sejak jaman nabi Luth dan perilaku LGBT merupakan dosa besar, seperti dijelaskan dalam AI Qur"an. Allah SWT berfirman:

Dan (kami juga telah mengutus) Luth (kepada kaumnya). (Ingatlah) tatkala Dia berkata kepada mereka: "Mengapa kamu mengerjakan perbuatan faahisyah (keji) itu, yang belum pernah dikerjakan oleh seorang pun (di dunia ini) sebelummu?' mendatangi lelaki untuk melepaskan nafsumu (kepada mereka), bukan kepada wanita,..." (Q.S. Al-A"raaf: 80-8I).

Survei SMRC yang dilakukan pada Maret 2016, September dan Desember 2017 dengan jumlah responden 1.220 orang. Berdasarkan survei tersebut hampir seluruh penduduk Indonesia menilai LGBT adalah ancaman. Sebanyak 87,6 persen berpendapat demikian. Jumlah tersebut sejalan dengan temuan berikutnya yaitu jika masalah LGBT dikaitkan dengan ajaran agama. Sebanyak 8I,5 persen penduduk Indonesia menilai LGBT dilarang agama, dan ini berlaku 
untuk semua agama (Tempo.co, 20I8). Berdasarkan hasil survei yang mengatakan bahwa LGBT adalah ancaman, dan dapat dikatagorikan sebagai bencana sosial karena akan mengakibatkan kerusakan pada moral remaja. Penelitian yang dilakukan oleh Ermayani, tahun 2017, yang berjudul "LGBT dalam Perspektif Islam". Penelitian ini dirancang untuk dapat memahamkan bahaya LGBT bagi orang tua dan guru dalam pendidikan anak. Penelitian ini merupakan penelitian kepustakaan (library research) dengan pendekatan psikologis analitik dan sosiologis. Hasil Penelitian LGBT dalam Perspektif Islam ini peneliti temukan karya otentik dan penelitian sebelumnya berupa buku yang bisa dijadikan acuan primer yang berjudul "Lo Gue Butuh Tau LGBT" yang menjelaskan tentang apa itu orientasi seksual, perubahan orientasi seksual, LGBT menurut Islam, Sikap kita terhadap SSA (Same Sexual Attraction) dan LGBT, menjaga diri dari LGBT, pacaran bukan solusi. Buku ini dilengkapi dengan suplemen tentang deteksi dini orientasi seksual dan kisah nyata dari klien yang mengalami SSA. Penelitian ini diharapkan dapat mencegah perilaku LGBT dengan bantuan orang dewasa. Bantuan dapat dilaksanakan melalui pendidikan karakter berlandaskan nilai-nilai Kemuhammadiyahan yang bertujuan untuk membentuk pribadi positif remaja.

Echols (Nata, 2018) Kosakata millenial berasal dari bahasa Inggris millennium atau millennia yang berarti masa seribu rahun. Millennia selanjutnya menjadi sebutan untuk sebuah masa yang terjadi setelah era global, atau era modern. Karena itu, era millennial dapat pula disebut erapost-modern. Era ini oleh sebagian pakar diartikan sebagai era back to spiritual and moral atau back to religion. Yaitu masa kembali kepada ajaran spiritual, moraldan agama. Era ini muncul sebagai respon terhadap era modern yang lebih mengutamakan akal, empirik, danhal-hal yang bersifat materialistik, sekularistik, hedonistik, fragmatik, dan transaksional. Yaitu pandangan yang memisahkan urusan dunia dengan urusan akhirat.

LGBT adalah istilah yang digunakan sejak tahun 1990-an, menurut Sinyo (Yansyah \& Rahayu, 2018) menggantikan frasa "komunitas gay" karena istilah ini dinilai lebih mewakili kelompok-kelompok yang "mengisi" istilah tersebut secara lebih rinci. LGBT Tinjauan pustaka tidak lebih dari 1000 kata dengan mengemukakan state of the art dalam bidang yang diteliti. Bagan dapat dibuat dalam bentuk JPG/PNG yang kemudian disisipkan dalam isian ini. Sumber pustaka/referensi primer yang relevan dan dengan mengutamakan hasil penelitian pada jurnal ilmiah dan/atau paten yang terkini. Disarankan penggunaan sumber pustaka 10 tahun terakhir. terdiri dari kelompok: I) Lesbi: kelompok wanita yang secara secara fisik, emosional, dan/atau spiritual merasa tertarik dengan wanita lain; 2) Gay: kelompok pria yang secara fisik, emosional, dan/atau spiritual merasa tertarik dengan pria lain; 3) Biseksual: kelompok orang yang secara fisik, emosional, dan/atau spiritual merasa tertarik baik kepada lawan jenis dan sesama jenis; 4) Transgender: kelompok orang yang merasa identitas gendernya berbeda dengan anatomi kelamin yang dimiliki, sehingga memilih/tidak memilih untuk melakukan operasi kelamin menyesuaikan dengan identitas gender yang diinginkan (APA: American Psychological Association, 2015). Definisi dari istilah LGBT berdasarkan kelomponya menurut Nugraha (2017) yaitu, (a) Lesbian yang dapat diartikan sebagai golongan indvidu yang dilahirkan secara biologis sebagai wanita, namun tertarik kepada wanita yang lain dari segi kecenderungan perasaannya maupun keinginan seksualnya; (b) gay adalah golongan yang dilahirkan secara biologis sebagai laki-laki, namun tertarik kepada sesame laki-laki yang lain, baik dari segi kecenderungan perasaannya maupun keinginan seksualnya; (c) Biseksual adalah seseorag yang mempunyai kecenderungan untuk tertarik kepada laki-laki maupun perempuan pada saat bersamaan. Sehingga kaum biseksual dapat menjalankan aktivitas seksual dengan dua orang yang berlainan kelamin tanpa merasa risih dan terganggu dengan indentitasnya; dan (d) transgender berbeda dengan golongan gay, lesbian dan biseksual karena golongan transgender tidak berorientasi pada dominasi kecenderungan perasaan maupun seksual pada sesama jenis.

Menurut Hesti dan Sugeng (Sa'dan, 2016) ada beberapa faktor penyebab terjadinya transeksual antara lain: Pertama, faktor biologis yang dipengaruhi oleh hormon seksual dan genetik seseorang. Kedua, faktor psikologi dan sosial budaya termasuk pula pola asuh lingkungan yang membesarkannya. Ketiga, memiliki pengalaman yang sangat hebat dengan lawan jenis sehingga mereka berkhayal dan memuja lawan jenis sebagai idola dan ingin menjadi seperti lawan jenis. Sigmund Freud (Hartini, 2018) merupakan seorang psikologis yang melihat gay sebagai akibat dari pola asuh dan kekerasan dari sang ayah. Kondisi ini dianggap bahwa sang anak laki-laki merasa gagal mendapatkan figure seorang ayah sehingga dirinya mulai muncul rasa mencintai dirinya sendiri atau mencintai sosok laki-laki. Kondisi bisexual merupakan hasil dari predis posisi sewaktu kecil. Hal ini berkembang mulai dari kehidupan anak-anak yang berada dalam lingkungan kehidupan heteroseksual ataupun lingkungan tertentu lainnya. Gangguan terjadi akibat ketidak matangan seksual yang 
menghasilkan kondisi homoseksual ketika dewasa. Kondisi homoseksual juga bisa terjadi akibat trauma masa kecil dimana pernah merasakan penyiksaan dari saudara kandung, teman ataupun orang tua.

Tidak hanya mempengaruhi kesehatan saja akan tetapi juga pribadi seseorang. Dari sudut sosiologi pula fenomena LGBT ini akan menyebabkan peningkatan gejala sosial dan maksiat hingga tidak dapat dikendalikan. jika dilihat dari sisi psikologi, kebiasaan jelek ini akan mempengaruhi kejiwaan dan memberi efek yang sangat kuat pada syaraf. Sebagai akibatnya pelaku merasa dirinya bukan lelaki atau perempuan sejati, dan merasa khawatir terhadap identitas diri dan seksualitasnya. Pelaku merasa cenderung dengan orang yang sejenis dengannya. Hal ini juga bisa memberi efek terhadap akal, menyebabkan pelakunya menjadi pemurung. Seorang homoseks selalu merasa tidak puas dengan pelampiasan hawa nafsunya (Gunawan \& Arif, 2017). Dampak yang paling berbahaya dari perilaku LGBT adalah terputusnya keturunan dari individu. Jika pernikahan sesama jenis dilakukan bagaimana manusia dapat berkembang biak. Tidak akan ada keturunan sebagai generasi penerus bangsa. Selain itu, rusaknya moral remaja karena melegalkan hubungan sesama jenis, kekerasn seksual yang juga dianggap sebagai sebuah konsekuensi yang wajar dari perilaku LGBT. kaum LGBT juga merasatidak puas dengan identitas seksual, sehingga menimbulakan gejala depresi.

Penelitian ini bertujuan mencegah LGBT pada generasi millenial melalui pendidikan karakter berlandaskan nilai-nilai Kemuhammadiyahan.

\section{METODOLOGI}

Metode penelitian yang digunakan dalam penelitian ini adalah metode pre-eksperimen. Menurut Creswell (2010:24I) rancangan penelitian mencakup satu kelompok yang diobservasi atau pengisian skala psikologi pada tahap pre-test yang kemudian dilanjutkan dengan treatment dan atau pengisian skala psikologi pada tahap posttest. Jenis metode eksprimen dalam penelitian ini adalah pre-eksperimental design dengan menggunakan one group pre-test dan post-test design. Penelitian yang dilaksanakan pada satu kelompok saja tanpa kelompok pembanding. Dalam penelitian ini atau pengisian skala psikologi dilakukan sebanyak dua kali yaitu sebelum eksperimen dan sesudah eksperimen.

Subjek dalam penelitian ini adalah peserta didik yang menjadi subjek penelitian yaitu 23 Peserta didik SMA Muhammadiyah I Palangkaraya. Teknik pengambilan subjek pada penelitian ini menggunakan purposive sampling. Sumber data yang digunakan dalam penelitian ini mengunakan beberapa instrumen yaitu: instrument psikologis berupa skala perilaku orientasi seksual. Analisi data yang digunakan dalam penelitian ini untuk meguji keefektivan pendidikan karakter berlandaskan nilainilai Kemuhammadiyahan adalah analisis data bevariat, teknik Paired-Sample T Test.

\section{HASIL DAN PEMBAHASAN}

Mitigasi pencegahan disorientasi seksual melalui pendidikan karakter berlandaskan nilai-nilai Kemuhammadiyahan pada generasi millenial dianalisis dengan menggunakan paired samples test pada 23 responden. Terjadi peningkatan skor setelah dilaksanakan intervensi. Hasil pretest dan posttest dapat dilihat pada tabel I berikut ini:

Tabel I. Hasil Pretest dan Posttest

\begin{tabular}{|c|c|c|c|c|c|}
\hline No & Responden & Pretest & Kategori & Posttest & Kategor \\
\hline I & $\mathrm{HJ}$ & 45 & Rendah & 100 & Sedang \\
\hline 2 & $A D$ & 66 & Rendah & 110 & Tinggi \\
\hline 3 & RM & 80 & Sedang & 117 & Tinggi \\
\hline 4 & YG & 53 & Rendah & 120 & Tinggi \\
\hline 5 & AS & 64 & Rendah & 132 & Tinggi \\
\hline 6 & $\mathrm{FR}$ & 58 & Rendah & 137 & Tinggi \\
\hline 7 & CAN & 75 & Sedang & 123 & Tinggi \\
\hline 8 & SDG & 70 & Rendah & 115 & Tinggi \\
\hline 9 & $\mathrm{VT}$ & 51 & Rendah & 116 & Tinggi \\
\hline 10 & NN & 50 & Rendah & 102 & Sedang \\
\hline 11 & $M N$ & 45 & Rendah & 98 & Sedang \\
\hline 12 & DFR & 62 & Rendah & 109 & Tinggi \\
\hline 13 & GS & 55 & Rendah & 116 & Tinggi \\
\hline 14 & $\mathrm{RH}$ & 48 & Rendah & 124 & Tinggi \\
\hline 15 & EKS & 50 & Rendah & $|3|$ & Tinggi \\
\hline 16 & DD & 72 & Sedang & 120 & Tinggi \\
\hline 17 & SLS & 54 & Rendah & 130 & Tinggi \\
\hline 18 & RLI & 51 & Rendah & 134 & Tinggi \\
\hline 19 & $\mathrm{KM}$ & 49 & Rendah & 122 & Tinggi \\
\hline 20 & LL & 56 & Rendah & 140 & Tinggi \\
\hline 21 & $\mathrm{RZ}$ & 62 & Rendah & 132 & Tinggi \\
\hline 22 & $\mathrm{SH}$ & 59 & Rendah & 110 & Tinggi \\
\hline 23 & YN & 46 & Rendah & 100 & Sedang \\
\hline
\end{tabular}

Berikut grafik hasil pretest dan posttest 23 responden sebelum diberi intervensi dan sesuah diberi intervensi dengan menggunakan pendidikan karakter berlandaskan nilainilai Kemuhammadiyahan 


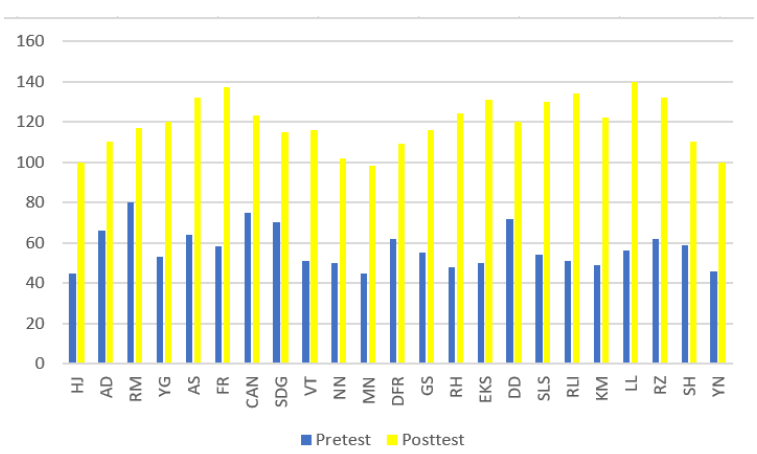

\section{Gambar I. Hasil Pretest dan Posttest}

Berdasarkan hasil analisis menggunakan paried sampels test, diperoleh peningkatan skor setelah intervensi, dapat dilihat pada tabel 2 , berikut ini:

\section{Tabel 2 Paired Samples Statistics}

Paried sampels test menunjukan bahwa 23 responden sebelum intervensi dengan menggunakan pendidikan karakter berlandaskan nilai-nilai Kemuhammadiyahan pada generasi millenial memiliki pemhan yang cenderung rendah tentang disorientasi seksual, sehingga dimungkinkan dapat terlibat perilaku LGBT. Setelah intervensi diperoleh peningkatan pemahaman ke 23 responden. Skor pretest adalah 57.43, terjadi peningkatan menjadi 119.04, diperoleh selisih peningkatan skor sebesar 61,97.

Tahun 1973 dari American Psychiatric Association untuk menghapus homoseksualitas dari DSM, homoseksualitas sekarang lebih umum dianggap sebagai varian normal dari seksualitas manusia. Teori variasi normal, memperlakukan homoseksualitas sebagai fenomena yang terjadi secara alami; bahwa individu homoseksual dilahirkan berbeda, tetapi alami, seperti orang kidal; dalam budaya kontemporer, teori ini mendasari keyakinan bahwa orang-orang "terlahir gay". Teori patologi, memperlakukan homoseksualitas dewasa sebagai penyakit, kondisi yang menyimpang dari "normal", perkembangan heteroseksual; tingkah laku atau perasaan gender atipikal adalah gejala penyakit; teori-teori ini menyatakan bahwa agen patogen eksternal menyebabkan homoseksualitas dan bahwa agen tersebut dapat bertindak sebelum atau sesudah kelahiran (paparan hormonal intrauterine, menjadi ibu yang berlebihan, ayah yang tidak memadai atau bermusuhan, pelecehan seksual, gangguan identitas gender). Teori ketidakdewasaan, menganggap aspek homoseksualitas di usia muda sebagai langkah normal menuju heteroseksualitas dewasa; idealnya, homoseksualitas adalah fase melewati untuk tumbuh; sebagai "penangkapan perkembangan," homoseksualitas dewasa terhambat pertumbuhannya (Glassgold \& Drescher, 2007).

Keberadaan LGBT di dunia sudah ada sejak lama, berawal dari waktu terawal fenomena tersebut ditemukan yaitu abad ke 19 an. Pada abad ke-19, American Psychiatric Assosiation (APA) masih menganggap homoseksualitas sebagai mental disorder. Seperti pada perkembangan diagnosis para psikiater di Amerika beserta risetnya, pada tahun 1952 diagnosis asli dan Statistik Manual of Mental Health (DSM) menetapkan bahwa homoseksual adalah gangguan kepribadian sosiopat. Sejalan dengan hal tersebut, pada tahun 1968 DSM menghapuskan homoseksual dari daftar sosiopat. Pada akhirnya karena terdapat efek politik di dalam tuntutan hak komunitas LGBT, tepatnya tahun 1973, American Psychiatric Association menghapus homoseksualitas dari DSM

\begin{tabular}{rlrrrr}
\hline & & Mean & $\mathrm{N}$ & \multicolumn{1}{c}{$\begin{array}{c}\text { Std. } \\
\text { Deviation }\end{array}$} & \multicolumn{1}{c}{$\begin{array}{c}\text { Std. Error } \\
\text { Mean }\end{array}$} \\
\hline \multirow{2}{*}{ Pair I } & Pretest & 57.43 & 23 & 9.958 & 2.076 \\
\cline { 2 - 6 } & Posttest & $\mathrm{I} 19.04$ & 23 & 12.426 & 2.591
\end{tabular}

dan menjelaskan bahwa homoseksualitas tidak lagi dianggap sebagai penyakit mental. Homoseksual dianggap sebagai perilaku biasa, namun menjadi masalah ketika orang homoseks tersebut mengalami kerugian atau ketidaknyamanan hingga harus diterapi (Santoso, 2016).

Menurut survey CIA pada tahun 2015 yang dilansir di topikmalaysia.com jumlah populasi LGBT di Indonesia adalah ke-5 terbesar di dunia setelah China, India, Eropa dan Amerika. Selain itu, beberapa lembaga survey independen dalam maupun luar negeri menyebutkan bahwa Indonesia memiliki $3 \%$ penduduk LGBT, ini berarti dari 250 juta penduduk 7,5 jutanya adalah LGBT, atau lebih sederhananya dari 100 orang yang berkumpul di suatu tempat 3 diantaranya adalah LGBT.

Ketua Komisi Fatwa MUI, AF Hasanuddin, lebih eksplisit dalam pandangannya yang menunjukkan bahwa LGBT adalah tindakan ilegal, kejahatan keji dan dosa berat, dan dapat dihukum dengan hukuman mati. Ketua Komisi Perlindungan Anak Indonesia (KPAl), Asrorun Niam, juga menyatakan bahwa sodomi lebih buruk daripada perzinahan dan seks di luar nikah, dan dihukum dengan hukuman keras. Said Aqil Siradj dari Nahdatul Ulama, menyatakan bahwa konsensus antara ahli hukum Islam sepakat bahwa seksualitas LGBT dilarang. Mengutip penjelasan dari Fakhruddin al-Razi, seorang komentator Islam ahli, Siradj, menyatakan bahwa perilaku homoseksual adalah tindakan keji, disebut sebagai al-fakhisyah (dosa besar) yang menjijikkan dan bertentangan dengan sifat manusia” (Muttaqin, 20l6). 
Muhammadiyah menolak dengan tegas LGBT dan semua hal yang mendukungnya, begitu pula para tokoh pendidikan di Indonesia, menganggap LGBT sebagai bentuk penyimpangan, oleh karena itu pemerintah harus tegas dalam mengatur eksistensi LGBT di Indonesia, para pelakunya perlu direhabilitasi agar kembali ke fitrahnya sebagai manusia yang heteroseksual, LGBT itu melanggar Hak Asasi Manusia (HAM) karena bertentangan dengan hak dasar manusia (Yansyah \& Rahayu, 2018).

Disebutkan dalam Q.S al-Syu'ara" (26) : ayat 165 dan 166. Artinya :

"Luth berkata kepada kaumnya): Mengapa kamu mendatangi (menggauli jenis laki-laki) di antara manusia" (QS. al-Syuara":I65)

"Dan kamu tinggalkan isteri-isteri yang dijadikan oleh Tuhanmu untukmu, bahkan kamu adalah orang orang yang melampaui batas". (QS. alSyuara": 166).

Ayat-ayat yang telah disebutkan menerangkan bahwa perbuatan kaum Nabi Luth yang hanya melakukan hubungan seksual kepada sesama laki-laki melepaskan syahwatnya hanya kepada sesama laki-laki dan tidak berminat kepada perempuan sebagaimana ditawarkan oleh Nabi Luth, tetapi mereka tetap melakukan perbuatan homoseksual, akhirnya Allah memberikan hukuman kepada mereka dan memutarbalikan negeri mereka, sehingga penduduk Sodom, termasuk isteri Nabi Luth kaum lesbi, tertanam bersamaan dengan terbaliknya negeri itu. Yang tidak kena azab hanya Nabi Luth dan pengikut-pengikutnya yang saleh dan menjauhkan diri dari perbuatan homoseks.

Akses informasi yang begitu mudah menjadi salah satu faktor kecepatan lintas budaya berbagai daerah bahkan negara, yang pada akhirnya meningkatkan peluang terjadinya pola perilaku yang berbeda-beda di masyarakat. Hal ini tidak terkecuali terjadi di Indonesia dengan budaya, demografi, tingkat pendidikan dan status sosial ekonomi yang sangat beragam.

Berbagai aspek masalah sosial dapat muncul sebagai kompensasi dari perkembangan tersebut. Diantara masalah yang akhir-akhir ini mendapat perhatian khusus dan kontroversi di kalangan praktisi, akademisi dan masyarakat luas adalah masalah orientasi seksual yang menyimpang, dimana kondisi tersebut belum mendapat persetujuan dari masyarakat luas, khususnya Indonesia (Siregar, 20I3). Kemenyimpangan ini pada dasarnya bukanlah hal baru dalam realitas kehidupan sosial, namun persoalan tersebut kembali mengemuka dan mengundang berbagai reaksi setelah pengesahan pernikahan sesama jenis oleh Mahkamah Agung Amerika Serikat (BBC News, 2015).

Munawwir (Yanggo, 2019) Islam sangat memperhatikan kesucian dan kehalalan. Agar manusia sehat dan cerdas secara emosional, intelektual dan spiritual maka semua yang dikonsumsi haruslah memenuhi kriteria suci dan halal .

a. Pengertian homoseksual

Homoseksual (gay) di dalam agama Islam disebut dengan istilah "al-liwath” (اللواط) yang berarti orang yang melakukan perbuatan seperti perbuatan kaum Nabi Luth, yang pelakunya disebut "al-luthiyyu" yang berarti laki-laki yang melakukan hubungan seksual dengan laki-laki.

b. Pengertian Lesbian

Istilah lesbian di dalam agama Islam disebut dengan sihaq (سحق) yang berarti perempuan yang melakukan hubungan seksual dengan sesama perempuan.

Abu Ahmad Muhammad Al Khidir bin Nursalim Al Limbory Al Mulky (Sukmanila, 2019) Di dalam Islam LGBT dikenal dengan dua istilah, yaitu Liwath (gay) dan Sihaaq (lesbian). Liwath (gay) adalah hubungan birahi yang terjadi antara sesama lelaki dengan cara memasukkan zakarnya ke dalam dubur laki-laki lain. Liwath merupakan penamaan yang dinisbatkan kepada kaum nabi Luth as. Hal ini disebabkan karena merekalah kaum yang pertama kali melakukan perbuatan ini.

LGBT adalah istilah yang digunakan sejak tahun 1990-an, menurut Sinyo (Yansyah \& Rahayu, 2018) menggantikan frasa "komunitas gay" karena istilah ini dinilai lebih mewakili kelompok-kelompok yang "mengisi" istilah tersebut secara lebih rinci. LGBT terdiri dari kelompok: I) Lesbi: kelompok wanita yang secara secara fisik, emosional, dan/atau spiritual merasa tertarik dengan wanita lain; 2) Gay: kelompok pria yang secara fisik, emosional, dan/atau spiritual merasa tertarik dengan pria lain; 3) Biseksual: kelompok orang yang secara fisik, emosional, dan/atau spiritual merasa tertarik baik kepada lawan jenis dan sesama jenis; 4) Transgender: kelompok orang yang merasa identitas gendernya berbeda dengan anatomi kelamin yang dimiliki, sehingga memilih/tidak memilih untuk melakukan operasi kelamin menyesuaikan dengan identitas gender yang diinginkan (APA: American Psychological Association, 2015).

Menurut Hesti dan Sugeng (Sa'm, 2016) ada beberapa faktor penyebab terjadinya transeksual antara lain: Pertama, faktor biologis yang dipengaruhi oleh hormon seksual dan genetik seseorang. Kedua, faktor psikologi dan sosial budaya termasuk pula pola asuh 
lingkungan yang membesarkannya. Ketiga, memiliki pengalaman yang sangat hebat dengan lawan jenis sehingga mereka berkhayal dan memuja lawan jenis sebagai idola dan ingin menjadi seperti lawan jenis.

Sigmund Freud (Hartini, 2018) merupakan seorang psikologis yang melihat gay sebagai akibat dari pola asuh dan kekerasan dari sang ayah. Kondisi ini dianggap bahwa sang anak laki-laki merasa gagal mendapatkan figure seorang ayah sehingga dirinya mulai muncul rasa mencintai dirinya sendiri atau mencintai sosok laki-laki. Kondisi bisexual merupakan hasil dari predisposisi sewaktu kecil. Hal ini berkembang mulai dari kehidupan anak-anak yang berada dalam lingkungan kehidupan heteroseksual ataupun lingkungan tertentu lainnya. Gangguan terjadi akibat ketidak matangan seksual yang menghasilkan kondisi homoseksual ketika dewasa. Kondisi homoseksual juga bisa terjadi akibat trauma masa kecil dimana pernah merasakan penyiksaan dari saudara kandung, teman ataupun orang tua.

Faktor seorang anak menyebabkan dirinya menjadi LGBT (Hartini, 2019)

a. Tidak percaya Tuhan (pikiran kosong) Pendidikan agama merupakan pondasi dasar bagi terbentuknya karakter seorang anak. Agama tidak hanya diberikan kepada si anak saat dia lahir, tapi sejak anak masih dalam kandungan si ibu, sudah dididik sejak dini. Kalau orang tua tidak mengajarkan anaknya dengan pendidikan agama yang cukup, maka akan mudah dipengaruhi dan akan merusak akhlak serta mentalnya tentang keberadaan tuhan.

b. Keluarga yang tidak memiliki pendirian, terlalu memberi kebebasan kepada anaknya. Keluarga yang tidak utuh, orang tua yang selalu memikirkan kepentingan sendiri dan meletakkan ego diatas segala-galanya maka yang akan terkena imbasnya adalah anak. Karena anak butuh panutan dan kasih sayang dari orang tua. Anak yang dibesarkan dengan materi saja, tidak cukup. Anak yang tumbuh tanpa pendidikan agama dan kasih sayang keluarga, maka kehancuran dan kerusakan moral yang akan terjadi.

c. Trauma masa lalu yang buruk terhadap lawan jenis (orang tua, kerabat dan yang lainnya). Masa lalu yang suram dan perlakuan yang tidak adil yang diterima si anak dimasa kecil, merupakan hal yang sangat dominan yang kelak akan membentuk kepribadian yang pintar dan cerdas.

d. Otak yang kurang cerdas. Otak yang cerdas belum tentu pintar, tapi otak yang pintar sudah pasti cerdas. Anak yang dibesarkan dengan pendidikan secara formal belum tentu cerdas, tapi anak yang dididik dengan formal dan informal, maka akan membentuk kepribadian yang pintar dan cerdas.

e. Ejekan yang terus menerus diterima sejak usia dini. Anak yang memiliki karakteristik seperti perempuan atau laki-laki di masa kecilnya, maka akan menjadi bahan olokan bagi teman temannya. Dan olokan serta ejekan itu yang terus-menerus dia terima lambat laun akan membentuk karakter kepribadiannya yang sebenarnya.

f. Kekaguman yang berlebihan kepada orang lain. Pada masa remaja, seorang anak sedang mencari jati dirinya. Dia mulai mengidolakan orang lain. Contohnya remaja sekarang lebih mengidolakan para artis korea yang gayanya lebih feminim atau maskulin. Sehingga remaja sekarang lebih banyak mengidolakan para artis yang gaya dan penampilannya seperti LGBT.

g. Hidup bergaul dengan orang-orang yang memiliki kelainan seksual (LGBT). Ini semacam virus yang akan terus merusak tatanan hidup generasi muda sekarang. Seorang remaja yang sering bergaul dengan lingkungan yang tidak sehat, maka dia akan mudah terpengaruh, apalagi tanpa ada landasan agama yang kuat.

h. Ingin diakui oleh orang lain (popular dan dipuji juga). Pembentukan karakter yang berlebihan agar diakui dan diterima oleh lingkungannya, sering membuat si anak melakukan tindakan yang berlebihan yang tidak sesuai dengan kemampuannya.

i. Doyan membaca berita hot dan konten pornografi lainnya. Peranan media saat ini sangat memprihatinkan, anak yang rentan disuguhkan tanpa ada sensor terlebih dahulu. Sehingga si anak dengan bebas bisa menonton dan bahkan meragakan adegan teman sebayanya.

j. Faktor ekonomi. Ini adalah faktor yang sangat fundamen sekali, karena anak remaja yang lepas kontrol terjun ke dunia LGBT karena faktor ekonomi, sebab mereka mendapatkan jaminan yang menjanjikan. Kerjanya mudah dan menghasilkan uang yang banyak.

Santrock (Hermawan \& Putra, 2017) Sejatinya, proses seorang anak mulai belajar mengidentifikasikan dirinya, apakah dia laki-laki atau perempuan berawal ketika individu berusia tiga tahun. Pada usia tiga tahun tersebut orang tua mulai memperkenalkan kepada anaknya bahwa ia adalah anak laki-laki atau anak perempuan, lengkap beserta peran ataupun kebiasaan-kebiasaan berdasarkan jenis kelaminnya. 
Orangtua Pun terus memberikan pembelajaran peran sesuai dengan jenis kelamin anak melalui jenis permainan yang diberikan, jenis baju yang digunakan, teman sepermainannya, pernak pernik yang dimiliki serta nilai-nilai yang diajarkan harus sesuai dengan jenis kelamin anak sejalan dengan semakin bertambahnya usia sang anak.. Baron (Hermawan \& Putra, 2017) Seorang anak mulai mengenal jenis kelaminnya secara permanen pada usia 6 - 7 tahun dengan memahami adanya perbedaan alat genital antara laki-laki dan perempuan.

West dan Zimmerman 1987, 127 (Westbrook \& Schilt, 2014) Proses kategorisasi ini, disebut "atribusi gender" atau "kategorisasi jenis kelamin", berteori sebagai ciri interaksi sosial sehari-hari yang tak terhindarkan tetapi biasanya biasa-biasa saja kecuali dalam kasus ambiguitas, yang dapat membuat gangguan interaksional, menimbulkan kecemasan, kekhawatiran, dan bahkan kemarahan (Schilt 2010). Proposisi tersebut mungkin berlaku dalam banyak interaksi non seksual, alat kelamin memainkan peran yang jauh lebih penting dalam penentuan gender dalam interaksi seksual dan seksual (Schilt dan Westbrook 2009).

\section{KESIMPULAN}

Hasil analisis menunjukan bahwa 23 responden sebelum intervensi memiliki pemhan yang cenderung rendah tentang disorientasi seksual, sehingga dimungkinkan dapat terlibat perilaku LGBT. Setelah intervensi diperoleh peningkatan pemahaman ke 23 responden. Skor pretest adalah 57.43, terjadi peningkatan menjadi 119.04, diperoleh selisih peningkatan skor sebesar 61,97. Mtigasi pencegahan disorientasi seksual melalui pendidikan karakter berlandaskan nilai-nilai Kemuhammadiyahan pada generasi millenial efektif mencegah perilaku LGBT.

\section{UCAPAN TERIMA KASIH}

Terima kasih kepada Direktorat Riset dan Pengabdian Masyarakat Direktorat Jenderal Riset dan Pengembangan Kementerian Riset, Teknologi, dan Pendidikan Tingg (RISTEKDIKTI) yang telah mendanai Penelitian Dosen Pemula dan kepada pihak LP2M Universitas Muhammadiyah Palangkaraya yang telah memfasilitasi dan melakukan pendampingan terhadap tim peneliti.

\section{REFERENSI}

American Psychological Association. (2018). Transgender people, gender identity and gender expression. Recopilado el, 6.

Berita BBC. (20I5). Legalisasi Pernikahan Sejenis di AS Kuatkan Gerakan di Indonesia. Diambil dari www.bbc.com/I50629 trensosisal_lgbt.html

Creswell, J.W. (2010). Research Desing. Pendekatan Kualitatif, Kuantitatif, dan Mixsed. Edisi Ketiga. Pustaka Pelajar. Yogyakarta

Chaplin, J. P., \& Kartono, K. (1989). Kamus lengkap psikologi. Rajawali Pers.

Fajarini, U., 20l4. Peranan kearifan lokal dalam pendidikan karakter. SOSIODIDAKTIKA: Social Science Education Journal, I(2), pp. I23-130.

Glassgold, J. M., \& Drescher, J. (2007). Activism and LGBT psychology: An introduction. Journal of Gay \& Lesbian Psychotherapy, I I(3-4), I-8.

Hall, M., \& Hall, J. (20II). The long-term effects of childhood sexual abuse: Counseling Implications. Pobrane z: http://counselingoutfitters. com/vistas/vistas I I/Article_19. pdf.

Huda, N. (2008). Kekerasan terhadap anak dan masalah sosial yang kronis. Pena Justisia Jurnal Media Komunikasi Dan Kajian Hukum, 7(14).

Hartini, Y. (2019). Politik Negara Terhadap Lesbian, Gay, Bisexual, And Transgender (LGBT) Di Indonesia (Studi Tentang Eksistensi Pelaku LGBT Di Kota Medan) (Doctoral dissertation, Universitas Islam Negeri Sumatera Utara).

Hermawan, R., \& Putra, B. H. S. (2017, August). Peran bimbingan konseling dalam komunitas lgbt. In Seminar Nasional Bimbingan Konseling Universitas Ahmad Dahlan (Vol. 2).

Kurnianingsih, S. (2003). Pelecehan Seksual terhadap Perempuan di Tempat Kerja. Buletin Psikologi, I I(2).

Kementrian Pendidikan dan Kebudayaan. 2014. Modul Assemen Pemantapan SMP

Klonsky, E. D., \& Moyer, A. (2008). Childhood sexual abuse and non-suicidal self-injury: metaanalysis. The British Journal of Psychiatry, 192(3), 166-170.

Lukman, A. A. (2018). Pewarisan Nilai Sebagai Pembentuk Kepribadian Berkarakter Melalui Falsafah Huma Betang Suku Dayak Kalimantan. Sosietas, 8(I).

Muttaqin, I. (2016). Membaca strategi eksistensi LGBT di Indonesia. Raheema: Jurnal Studi Gender Dan Anak, 3. 
Navalta, C. P., Polcari, A., Webster, D. M., Boghossian, A., \& Teicher, M. H. (2006). Effects of childhood sexual abuse on neuropsychological and cognitive function in college women. The Journal of Neuropsychiatry and Clinical Neurosciences, 18(I), 45-53.

Permana, C. E., Nasution, I. P., \& Gunawijaya, J. (20I2). Kearifan lokal tentang mitigasi bencana pada masyarakat Baduy. Hubs-Asia, 9(2).

Ramdhani, M.A., (20I7). Lingkungan Pendidikan dalam Implementasi Pendidikan Karakter. Jurnal Pendidikan UNIGA, 8(I), Pp.28-37. Daftar pustaka disusun dan ditulis berdasarkan sistem nomor sesuai dengan urutan pengutipan. Hanya pustaka yang disitasi pada usulan penelitian yang dicantumkan dalam Daftar Pustaka.

Rusni, R. (20I7). Fenomena Kekerasan Seksual Terhadap Anak. Shautut Tarbiyah, 35(2), 5I68.

Snyder, H. N. (2000). Sexual assault of young children as reported to law enforcement: Victim, incident, and offender characteristics. Washington, DC: U.S. Department of Justice, Office of Justice Programs, Bureau of Justice Statistics. Retrieved January 12, 2009 fromhttp://www.ojp.usdoj.gov/bjs/pub/pdf/sa ycrle.pdf

Suyanto, B. (2010). Masalah sosial anak. Kencana.

Santoso, M. B. (20 I6). LGBT dalam Perspektif Hak Asasi Manusia. Share: Social Work Journal, 6(2), 220.

Wardhani, Y. F., \& Lestari, W. (2007). Gangguan Stres Pasca Trauma pada Korban Pelecehan Seksual dan Perkosaan. Pusat Penelitian dan Pengembangan Sistim dan Kebijakan Kesehatan: Surabaya.

Westbrook, L., \& Schilt, K. (20I4). Doing gender, determining gender: Transgender people, gender panics, and the maintenance of the sex/gender/sexuality system. Gender \& Society, 28(I), 32-57

Yansyah, R., \& Rahayu, R. (2018). Globalisasi lesbian, gay, biseksual, dan transgender (Lgbt): perspektif HAM dan agama dalam lingkup hukum di Indonesia. Law Reform, I4(I), I32146.

Yanggo, H. T. (2019). Penyimpangan Seksual (LGBT) Dalam Pandangan Hukum Islam. MISYKAT: Jurnal IImu-ilmu Al-Quran, Hadist, Syari'ah dan Tarbiyah, 3(2), I-28.
Zai, A., \& Siregar, T. (20II). Perlindungan Hukum terhadap Anak yang Berhadapan dengan Hukum dalam Sistem Peradilan Anak (Studi pada Wilayah Hukum Polres Nias). Jurnal Mercatoria, 4(2), 99-116.

http://kalteng.prokal.co/read/news/3 187-kasuspelecehan-seksual-terus-meningkat.html. Diakses 03 Agustus 2018. 